\title{
Determination of Trace Antimony (III) by Adsorption Voltammetry at Carbon Paste Electrode
}

\author{
Huishi Guo ${ }^{1,2, *}$, Yiheng $\mathrm{Li}^{3}$, Xiaokang Chen ${ }^{1}$, Libo $\mathrm{Nie}^{2}$ and Nongyue He ${ }^{2, *}$ \\ ${ }^{1}$ Department of Chemistry, Shaoguan University, Shaoguan, 512005, China \\ 2 State Key Laboratory of Bioelectronics (Chien-Shiung Wu Laboratory), Southeast University, \\ Nanjing 210096, China \\ 3 Department of Chemistry, Xiangtan University, Xiangtan, 411105, China \\ *Author to whom correspondence should be addressed. E-mail: nyhe1958@163.com; \\ guohuishi@163.com
}

Received: 12 July 2004 / Accepted: 2 May 2005 / Published: 4 May 2005

\begin{abstract}
This work presents a sensitive method for the determination of trace antimony based on the antimony-pyrogallol red (PGR) adsorption at a carbon paste electrode (CPE). The optimal conditions were to use an electrode containing $25 \%$ paraffin oil and $75 \%$ high purity graphite powder as working electrode, a $0.10 \mathrm{~mol} / \mathrm{L} \mathrm{HCl}$ solution containing $3.0 \times 10^{-5} \mathrm{~mol} / \mathrm{L}$ PGR as accumulation medium and a $0.20 \mathrm{~mol} / \mathrm{L} \mathrm{HCl}$ solution as electrolyte with an accumulation time of $150 \mathrm{~s}$ and a reduction time of $60 \mathrm{~s}$ at $-0.50 \mathrm{~V}$ followed with a sweep from $-0.50 \mathrm{~V}$ to $0.20 \mathrm{~V}$. The mechanism of the electrode reaction was discussed. Interferences of other metal ions were studied as well. The detection limit was $1 \times 10^{-9} \mathrm{~mol} / \mathrm{L}$. The linear range was from $2.0 \times 10^{-9} \mathrm{~mol} / \mathrm{L}$ to $5.0 \times 10^{-7} \mathrm{~mol} / \mathrm{L}$. Application of the proposed method to the determination of antimony in water and human hair samples gave good results.
\end{abstract}

Keywords: antimony, pyrogallol red, carbon paste electrode, adsorptive voltammetry.

\section{Introduction}

Antimony (Sb), in trace and ultratrace amounts, is an important element in biological and environmental systems. It is a toxic element and seriously harmful to human health. It is considered as pollutant of priority interest by the Environmental Protection Agency of the United States and the Council of the European Communities. Therefore, it is not surprising that various methods have been developed for Sb determination [1-4]. Among these methods electrochemical stripping analysis is 
favored for its high sensitivity, low cost, as well as easy and rapid operation.

Pyrogallol red (PGR), a metal sensitive dye, is a widely used hydroxyketone ligand with the structure shown in Figure 1. It has been applied to the determination of various substances such as tin (IV) [5], copper (II) [6], nitrite [7], and proteins [8].

The application of carbon paste electrode (CPE) has attracted considerable attention in recent years. CPEs have several advantages such as nontoxic, low background current, wide range of used potential, rapid renewal, and easy fabrication [9-10]. We have reported a pyrogallol red modified carbon paste electrode for the determination of Sb (III) [11]. Though this method was found to be sensitive, it was only applied to spiked samples due to the serious interference of $\mathrm{Cu}$ (II). The aim of this work was to develop a simple, selective and sensitive method for the determination of Sb (III) by adsorptive voltammetry on CPE in real samples.

\section{Experimental}

\section{Reagents and solutions}

Chemicals were of analytical reagent grade unless otherwise stated. A $1.0 \times 10^{-3} \mathrm{~mol} / \mathrm{L}$ antimony (III) stock solution was prepared by dissolving an appropriate amount of antimony oxide in $6 \mathrm{~mol} / \mathrm{L}$ HCl. Pyrogallol red (PGR, Sigma) solution $\left(1 \times 10^{-3} \mathrm{~mol} / \mathrm{L}\right)$ was prepared by dissolving PGR (0.1001 g) in ethanol $(100 \mathrm{~mL})$, then diluting to $250 \mathrm{~mL}$ with double distilled water. Carbon paste was prepared by thoroughly mixing $0.5 \mathrm{~g}$ of paraffin oil with $1.5 \mathrm{~g}$ of high purity graphite powder. All other solutions were prepared using standard laboratory procedures. Double distilled water was used throughout.<smiles>O=c1ccc2c(-c3ccccc3S(=O)(=O)O)c3ccc(O)c(O)c3oc-2c1O</smiles>

Figure 1. The structure of pyrogallol red (PGR).

\section{Apparatus}

A JP-303 polarographic analyzer (Chengdu Instrument Factory) was used for the electrochemical experiments. A working carbon paste electrode was prepared by packing carbon pastes into a glass tube (4 mm inner diameter) with a stainless steel rod as the electric contact. The surface of working electrode was polished on a sheet of graph paper. This working electrode was used together with a platinum wire counter electrode and a saturated calomel reference electrode (SCE). A magnetic stirrer 
(Shanghai Analytical Instrument Company) with a Teflon-coated stirring bar was used in the accumulation, cleaning and rinsing steps.

\section{Procedure}

The electrode surface was immersed in a preconcentration solution $(0.10 \mathrm{~mol} / \mathrm{L} \mathrm{HCl})$ which contains an appropriate concentration of $\mathrm{Sb}$ (III) and $3.0 \times 10^{-5} \mathrm{~mol} / \mathrm{L}$ PGR, and the accumulation of Sb (III)-PGR complex onto the electrode surface was achieved at open circuit, under constant stirring. After the accumulation, the electrode was removed, rinsed with water and dried with absorbent paper. Then it was introduced into the separate voltammetric cell containing only a supporting electrolyte $(0.20 \mathrm{~mol} / \mathrm{L} \mathrm{HCl})$. A cathodic potential $(-0.50 \mathrm{~V})$ was applied for $60 \mathrm{~s}$ in the quiescent supporting medium to ensure the reduction of the accumulated species. Finally, the second-order derivative voltammogram was recorded by applying a potential scan at a scan rate of 100 $\mathrm{mV} / \mathrm{s}$ from $-0.50 \mathrm{~V}$ to $0.20 \mathrm{~V}$. The same electrode surface could be reused without any treatment for at least 30 successive experiments. Further use required a renewal of the electrode surface by mechanical smoothing, similarly as reported elsewhere [9-10]. All experiments were performed at room temperature and it was not necessary to remove oxygen from the solution.

\section{Results and Discussion}

\section{Adsorptive and voltammetric characteristics of the Sb (III)-PGR complex on CPE}

As shown in Figure 2, curve 1, no peak was found when the CPE was processed according to the procedure showed above in a solution only containing $1.0 \times 10^{-7} \mathrm{~mol} / \mathrm{L} \mathrm{Sb}$ (III). Anodic stripping voltammograms (ASVs) were obtained in the solution of PGR without (Figure 2, curve 2) and with (Figure 2, curve 3) Sb (III). The ASV in the solution of PGR without Sb (III) did not show any current peak in the potential range used, whereas the ASV in the solution of PGR with Sb (III) illustrated a sensitive anodic peak at about $0.08 \mathrm{~V}$. It seems clear that the Sb (III)-PGR complex in the solution can be accumulated onto the electrode surface during the preconcentration period, and, then reduced to $\mathrm{Sb}(0)$ during the reduction interval. The anodic peak at about $0.08 \mathrm{~V}$ corresponds to the oxidation of $\mathrm{Sb}(0)$ on the electrode surface to $\mathrm{Sb}(\mathrm{III})$.

Figure 3 shows the plots of the peak current varying with the accumulation time $\left(t_{a}\right)$ for $1.0 \times 10^{-7} \mathrm{~mol} / \mathrm{L}$ and $5.0 \times 10^{-8} \mathrm{~mol} / \mathrm{L} \mathrm{Sb}$ (III), respectively. The trends were nearly the same as those obtained from this kind of electrode [9-11], i.e., both curves showed initially linear behavior, stripping peak current increased with an increasing accumulation time until the peak current reached a plateau, which indicates adsorption equilibrium was achieved. The plots in Figure 3 also displayed a steeper slope at higher concentration of Sb (III), pointing to a higher rate of uptake of Sb (III)-PGR complex on the electrode surface and a longer accumulation time required to reach the current plateau at a lower concentration of Sb (III). A preconcentration time of $150 \mathrm{~s}$ was selected for further studies in order to keep the linear relationship at a higher concentration level of Sb (III). 


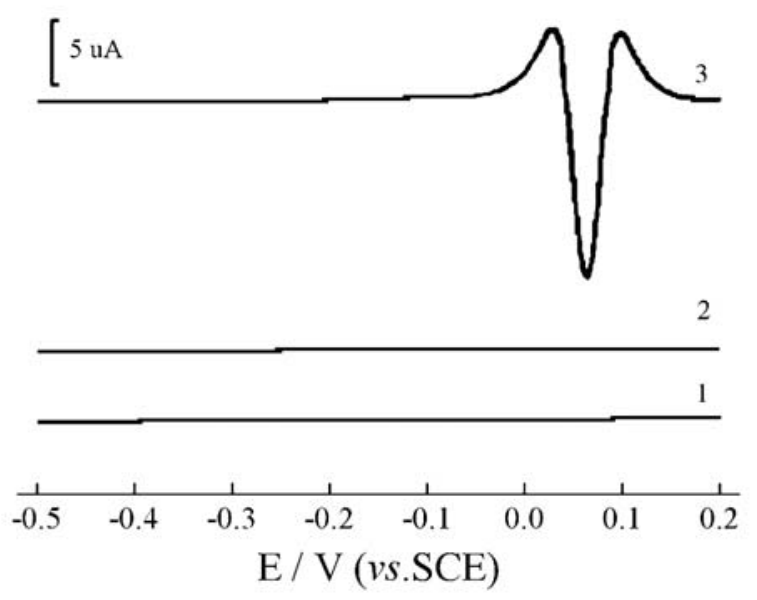

Figure 2. Anodic stripping curves of (1) $1.0 \times 10^{-7} \mathrm{~mol} / \mathrm{L} \mathrm{Sb}$ (III); (2) $3.0 \times 10^{-5} \mathrm{~mol} / \mathrm{L}$ PGR; (3) $1.0 \times 10^{-7} \mathrm{~mol} / \mathrm{L} \mathrm{Sb}(\mathrm{III})+3.0 \times 10^{-5} \mathrm{~mol} / \mathrm{L}$ PGR. Preconcentration medium, $0.10 \mathrm{~mol} / \mathrm{L} \mathrm{HCl}$; preconcentration time: $150 \mathrm{~s}$; reduction and stripping medium, $0.20 \mathrm{~mol} / \mathrm{L} \mathrm{HCl}$; reduction time and potential: $60 \mathrm{~s},-0.50 \mathrm{~V}$; scan rate: $100 \mathrm{mV} / \mathrm{s}$.

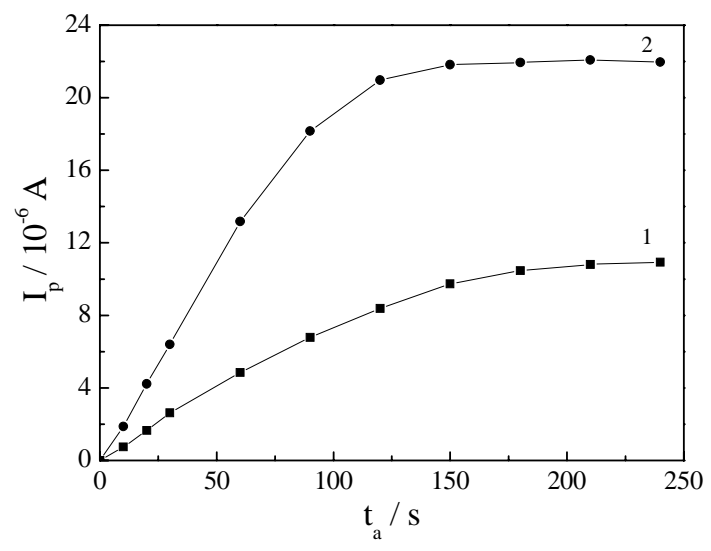

Figure 3. Effect of preconcentration time on the peak current. Open-circuit preconcentration in (1) $5.0 \times 10^{-8} \mathrm{~mol} / \mathrm{L} \mathrm{Sb}(\mathrm{III})$; (2) $1.0 \times 10^{-7} \mathrm{~mol} / \mathrm{L} \mathrm{Sb}$ (III). Other conditions as in Figure 2, curve 3.

In order to further investigate the behavior of the Sb (III)-PGR complex on the CPE, cyclic voltammetry was adopted. Figure 4 displays cyclic voltammograms (CVs) after preconcentration for $150 \mathrm{~s}$ on CPEs in $0.10 \mathrm{~mol} / \mathrm{L} \mathrm{HCl}$ solution containing $1.0 \times 10^{-6} \mathrm{~mol} / \mathrm{L} \mathrm{Sb}$ (III) and $3.0 \times 10^{-5} \mathrm{~mol} / \mathrm{L}$ PGR (curve 1). The anodic peak at $0.08 \mathrm{~V}$ corresponds to the oxidation of $\mathrm{Sb}(0)$ on the electrode surface to $\mathrm{Sb}$ (III), and the cathodic peak at $-0.30 \mathrm{~V}$ corresponds to the reduction of Sb (III) in the Sb (III)-PGR complex to $\mathrm{Sb}(0)$. The fact that the peak current rapidly decreased upon repetitive scanning (curve 2) indicates the $\mathrm{Sb}(0)$ precipitated on the electrode surface can be completely stripped into the supporting electrolyte, which conduced to the renewal of the electrode surface. 


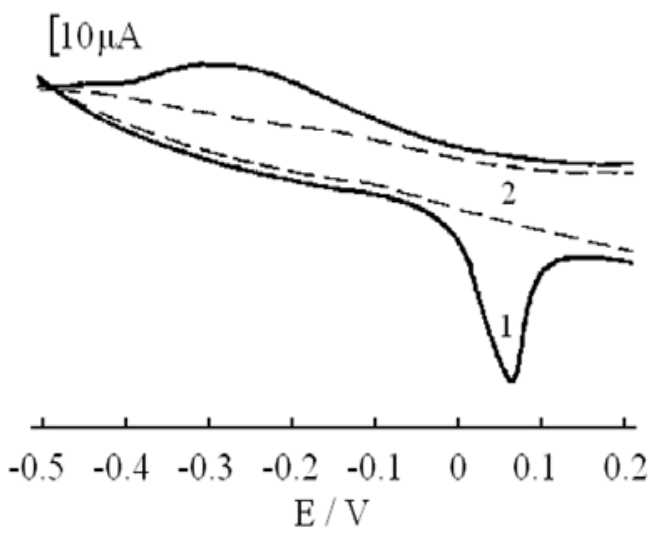

Figure 4. Cyclic voltammograms of the CPE preconcentration in $0.10 \mathrm{~mol} / \mathrm{L} \mathrm{HCl}$ solution containing $1.0 \times 10^{-6} \mathrm{~mol} / \mathrm{L} \mathrm{Sb}$ (III) and $3.0 \times 10^{-5} \mathrm{~mol} / \mathrm{L}$ PGR. (1) the first scan; (2) the repetitive scan. Scan rate: $50 \mathrm{mV} / \mathrm{s}$, other conditions as in Figure 2, curve 3.

\section{Selection of the adhesive in the electrode}

Mineral butter, silicon oil, solid paraffin and liquid paraffin were tested as the adhesive of the CPE. It was found that liquid paraffin was the best choice for the highest sensitivity. The effect of paraffin oil content in the CPE was investigated as well. It was found that too high oil contents would increase the hydrophobic character of the electrode surface, limiting somewhat the adsorption of Sb (III)-PGR complex onto the CPE surface. However, at the same time too low oil loadings resulted in rather poor reproducibility due to the lack in compaction of the electrode materials. Hence, CPEs containing 25\% paraffin oil were employed in all subsequent experiments.

\section{Effect of the supporting medium}

Seven media, namely sodium hydroxide, phosphate buffer, Britton-Robinson buffer, acetate buffer, sulfuric acid, nitric acid and hydrochloric acid were tested as accumulation supporting media. It was found that sulfuric acid, nitric acid and hydrochloric acid were outstanding in terms of peak shape and sensitivity. Among these three media, the best peak shape was obtained in hydrochloric acid. When the concentration of hydrochloric acid was $0.10 \mathrm{~mol} / \mathrm{L}$, the highest peak height was obtained. A $0.10 \mathrm{~mol} / \mathrm{L}$ $\mathrm{HCl}$ solution was chosen as accumulation supporting medium accordingly.

Solutions discussed above were also examined as stripping electrolyte medium. A sensitive and shapely peak was obtained when a $0.20 \mathrm{~mol} / \mathrm{L} \mathrm{HCl}$ solution was used. Therefore, a $0.20 \mathrm{~mol} / \mathrm{L} \mathrm{HCl}$ solution was selected as reduction and stripping medium for further studies.

\section{Effect of the concentration of PGR}

Figure 5 shows the effect of variation of PGR concentration on the peak current. The peak current increased with increasing PGR concentration up to $2.0 \times 10^{-5} \mathrm{~mol} / \mathrm{L}$ and remained constant when the concentration of PGR was in the range from $2.0 \times 10^{-5} \mathrm{~mol} / \mathrm{L}$ to $4.0 \times 10^{-5} \mathrm{~mol} / \mathrm{L}$. Higher concentration of PGR led to somewhat decrease of the peak current, which was most probably due to the competitive adsorption of PGR and Sb (III)-PGR complex on the CPE surface. Thus, an optimum PGR 
concentration of $3.0 \times 10^{-5} \mathrm{~mol} / \mathrm{L}$ was selected for further experiments.

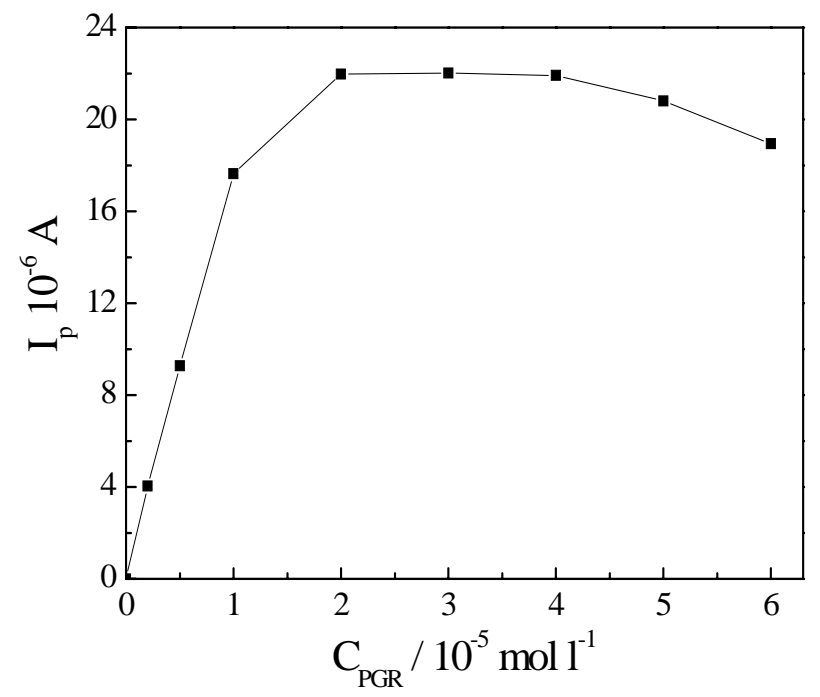

Figure 5. Effect of PGR concentration on the peak current. Other conditions as in Figure 2, curve 3.

\section{Effect of the reduction potential and time}

The peak current increased sharply with negative-going reduction potential up to $-0.40 \mathrm{~V}$ and then remained constant till $-0.55 \mathrm{~V}$ (Figure 6). When the reduction potential was more negative than $-0.60 \mathrm{~V}$, the peak current decreased rapidly, which was due to the fact that hydrogen ions in the aqueous solution were reduced to hydrogen and, therefore, led to the exfoliation of the Sb (0) from the electrode surface. Accordingly, $-0.50 \mathrm{~V}$ was selected as the reduction potential for all subsequent studies. Under this reduction potential, a $60 \mathrm{~s}$ of reduction time $\left(t_{r}\right)$ was judged to be sufficient and was therefore favored (Fig. 7).

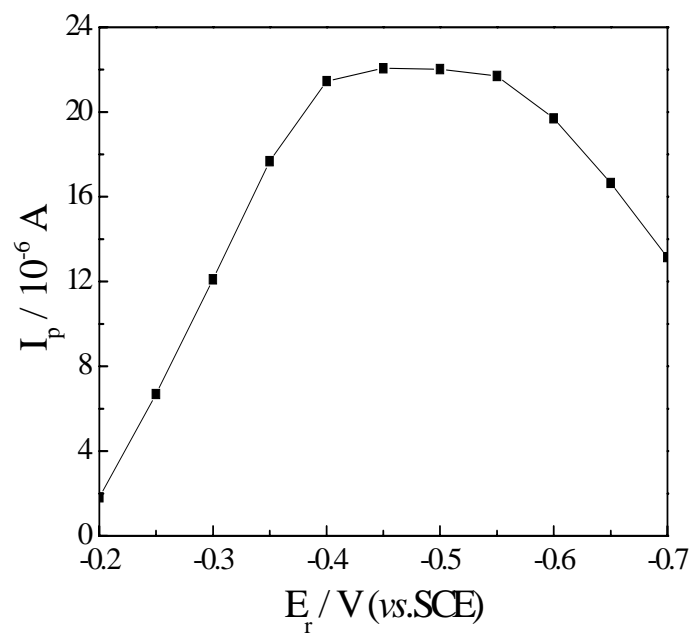

Figure 6. Effect of reduction potential on the peak current. Other conditions as in Figure 2 curve 3. 


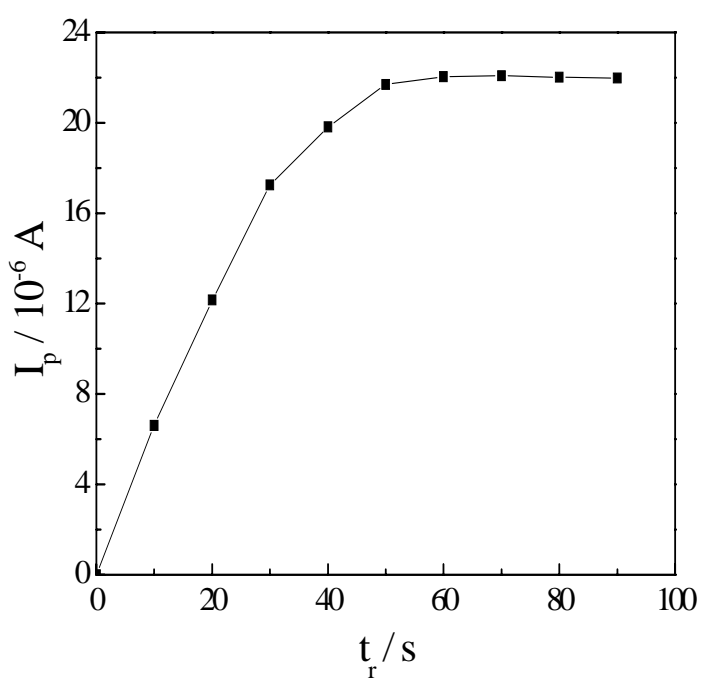

Figure 7. Effect of reduction time on the peak current. Other conditions as in Figure 2, curve 3.

\section{Linear range and detection limit of the method}

The second-order derivative peak current increased linearly with Sb (III) concentration over the range from $2.0 \times 10^{-9} \mathrm{~mol} / \mathrm{L}$ to $5.0 \times 10^{-7} \mathrm{~mol} / \mathrm{L}$. The detection limit (three times signal to noise) was found to be $1 \times 10^{-9} \mathrm{~mol} / \mathrm{L}$ with a preconcentration time of $150 \mathrm{~s}$ and a reduction time of $60 \mathrm{~s}$. After the CPE was activated, the relative standard deviation (R.S.D.) of $4.7 \%$ was obtained by ten successive determinations of $1.0 \times 10^{-7} \mathrm{~mol} / \mathrm{L} \mathrm{Sb}(\mathrm{III})$.

\section{Interference studies}

To check the selectivity of the proposed stripping voltammetric method for the Sb (III) ions, various metal ions, as potential interferents, were tested. The results showed that less than a 500-fold molar excess of $\mathrm{Ca}^{2+}, \mathrm{Mg}^{2+}, \mathrm{Zn}^{2+}, \mathrm{Ba}^{2+}$; a 100-fold molar excess of $\mathrm{Al}^{3+}, \mathrm{Fe}^{3+}, \mathrm{Cr}^{3+}, \mathrm{Mn}^{2+}$; a 50-fold molar excess of $\mathrm{Fe}^{2+}, \mathrm{Co}^{2+}, \mathrm{Ni}^{2+}$, Ga (III), Ge (IV), Se (IV), Ti (IV), V (V); a 20-fold molar excess of $\mathrm{Cd}^{2+}, \mathrm{Hg}^{2+}$, As (III), Sn (IV); a 10-fold molar excess of $\mathrm{Pb}^{2+}, \mathrm{Bi}^{3+}, \mathrm{Ag}^{+}$and 5-fold molar excess of $\mathrm{Cu}^{2+}$ did not interfere the determination of $1.0 \times 10^{-7} \mathrm{~mol} / \mathrm{L} \mathrm{Sb}(\mathrm{III})$. When adding $1.0 \times 10^{-3} \mathrm{~mol} / \mathrm{L}$ sodium oxalate into the accumulation medium, the sustainable coexistent concentration of $\mathrm{Cu}^{2+}, \mathrm{Pb}^{2+}$ and $\mathrm{Bi}^{3+}$ could be increased up to 50-fold, 100-fold and 100-fold molar excess over Sb (III), respectively.

\section{Analytical applications}

The proposed method was applied to the determination of antimony in water and human hair samples. Samples were pretreated according to [12] and [13] and concentrated to a suitable volume by slowly heating evaporation before the determination. A proper amount of $\mathrm{Na}_{2} \mathrm{C}_{2} \mathrm{O}_{4}$ was added to the sample solution to obtain a final concentration of $1.0 \times 10^{-3} \mathrm{~mol} / \mathrm{L}$. A suitable volume was transferred into a cell for the determination of antimony, using the procedure described above. The results, summarized in Tables 1 and 2, showed satisfactory recoveries. 
Table 1. Determination results of antimony in water samples $(n=5)$.

\begin{tabular}{cccccc}
\hline Sample & $\begin{array}{c}\text { Found } \\
(\mu \mathrm{g} / \mathrm{L})\end{array}$ & $\begin{array}{c}\text { R.S.D. } \\
(\%)\end{array}$ & $\begin{array}{c}\text { Added Sb }^{3+} \\
(\mu \mathrm{g} / \mathrm{L})\end{array}$ & $\begin{array}{c}\text { Total found } \\
(\mu \mathrm{g} / \mathrm{L})\end{array}$ & $\begin{array}{c}\text { Recovery } \\
(\%)\end{array}$ \\
\hline Tap water & 0.24 & 3.8 & 0.50 & 0.72 & 96 \\
River water & 0.32 & 4.2 & 0.50 & 0.83 & 102 \\
Waste water & 1.68 & 4.7 & 0.50 & 2.17 & 98 \\
\hline
\end{tabular}

Table 2. Determination results of antimony in human hair samples $(n=5)$.

\begin{tabular}{llllll}
\hline Sample & $\begin{array}{l}\text { Found } \\
(\mu \mathrm{g} / \mathrm{g})\end{array}$ & $\begin{array}{l}\text { R.S.D. } \\
(\%)\end{array}$ & $\begin{array}{l}\text { Added Sb } \\
(\mu \mathrm{g} / \mathrm{g})\end{array}$ & $\begin{array}{l}\text { Total found } \\
(\mu \mathrm{g} / \mathrm{g})\end{array}$ & $\begin{array}{c}\text { Recovery } \\
(\%)\end{array}$ \\
\hline Human hair 1 & 6.57 & 3.4 & 5.00 & 11.49 & 98.4 \\
Human hair 2 & 5.88 & 5.3 & 5.00 & 11.06 & 103.6 \\
\hline
\end{tabular}

\section{Conclusions}

This paper showed that the pyrogallol red is a useful ligand for the highly sensitive and selective determination of Sb (III) by adsorptive stripping voltammetry at CPE. The cheap, nonpoisonous CPE was used instead of the severe toxic, expensive mercury electrode in this method. Thus, it has excellent environmental and economical benefit. In this method, the accumulation was achieved by non-electrochemical deposition step and the stripping analysis was performed in a pure electrolyte solution. This approach not only enhanced the sensitivity but also eliminated the majority of the interferences from the sample background. Compared with the determination method of antimony based on CPE previously reported [11], the method presented here had a lower detection limit and a higher selectivity (not interfered so strongly by other metal ions). The determination results of trace antimony in water and human hair samples gave good results.

\section{Acknowledgements}

This research was supported by the Natural Science Foundation of China, the Trans-Century Training Programme Foundation for the Talents by the Ministry of Education of China, the Chinese Post Doctoral Science Foundation, the Natural Science Research Program of Education Department of Guangdong Province (Z02078), and the Science and Technology Research Program of Guangdong Province.

\section{References}

1. Kubota, T.; Kawakami, A.; Sagara, T.; Ookubo, N.; Okutani, T. Determination of antimony content in natural water by graphite furnace atomic absorption spectrometry after collection as antimony (III)-pyrogallol complex on activated carbon. Talanta 2001, 53, 1117. 
2. Deng, T.L.; Chen, Y.W.; Belzile, N. Antimony speciation at ultra trace levels using hydride generation atomic fluorescence spectrometry and 8-hydroxyquinoline as an efficient masking agent. Anal. Chim. Acta 2001, 432, 293.

3. Quentel, F.; Filella, M. Determination of inorganic antimony species in seawater by differential pulse anodic stripping voltammetry: stability of the trivalent state. Anal. Chim. Acta 2002, 452, 237.

4. Tanaka, T.; Ishiyama, T.; Okamoto, K. Determination of Antimony in Steel by Differential Pulse Anodic Stripping Voltammetry at a Rotating Gold Film Electrode. Anal. Sci. 2000, 16, 19.

5. Long, H.; Hou, X.F.; Li, Y.H. Polarographic Adsorptive Catalytic Wave of Tin (IV)-Pyrogallol Red-Vanadium (IV)-Sodium Dodecyl Sulfonate System. Chin. J. Anal. Chem. 1999, 27, 316.

6. Safavi, A.; Shams, E. Determination of trace amounts of copper (II) by adsorptive stripping voltammetry of its complex with pyrogallol red. Anal. Chim. Acta 1999, 385, 265.

7. Kazemzadeh, A.; Ensafi, A.A. Simultaneous determination of nitrite and nitrate in various samples using flow-injection spectrophotometric detection. Microchem. J. 2001, 69, 159.

8. Williams, K.M.; Marshall, T. Protein concentration of cerebrospinal fluid by precipitation with Pyrogallol Red prior to sodium dodecyl sulphate-polyacrylamide gel electrophoresis. J. Biochem. Biophys. Methods 2001, 47, 197.

9. Mousavi, M.F.; Rahmani, A.; Golabi, S.M.; Shamsipur, M.; Sharghi, H. Differential pulse anodic stripping voltammetric determination of lead (II) with a 1,4-bis(prop-2'-enyloxy)-9,10-anthraquinone modified carbon paste electrode. Talanta 2001, 55, 305.

10. Abbaspour, A.; Moosavi, S.M.M. Chemically modified carbon paste electrode for determination of copper (II) by potentiometric method. Talanta 2002, 56, 91.

11. Guo, H.S.; Li, Y.H.; Xie, H.Q. Determination of Trace Antimony by Adsorptive Stripping Voltammetry with Pyrogallol Red Modified Carbon Paste Electrode. Nat. Sci. J. of Xiangtan Univ. 2001, 23, 68.

12. Wei, X.Y.; Tan, J.X. Polarographic Adsorptive Complex Catalytic Wave of Antimony (III) and Tin (IV) with 7-Iodo-8-hydroxyquinolin-5-sulfonic Acid (Ferron) and Its Application. Fenxi Shiyanshi 1996, 15, 58.

13. Zhang, X.L.; Ma, C.S.; Wang, L.Z.; Zhang, J.G. Trace adsorptive voltammetric determination of antimony in hair. Talanta 1995, 42, 897.

(c) 2005 by MDPI (http://www.mdpi.net). Reproduction is permitted for noncommercial purposes. 